\title{
AS MIGRAÇÕES PARTIDÁRIAS E O CALENDÁRIO ELEITORAL ${ }^{1}$
}

\author{
Simone Diniz \\ Universidade de São Paulo
}

\begin{abstract}
RESUMO
Pesquisas sobre "migração partidária" são relativamente recentes no nosso país, embora a literatura muitas vezes aponte esse fenômeno como mais um sinal da não-institucionalização do nosso sistema partidário. Parte dos especialistas que trataram do tema tendem a apontar a não-coibição da legislação como a principal causa das migrações. Este artigo defende o argumento que não é ausência da coibição, mas o ganho a ser obtido com a mudança o fator que explicaria a troca de legenda.
\end{abstract}

PALAVRAS-CHAVE: migração partidária; sistema partidário; sistema eleitoral; propaganda eleitoral gratuita.

O sistema partidário brasileiro tende a ser caracterizado como um sistema composto por um excessivo número de partidos políticos, sem enraizamento social e com alto índice de fragmentação partidária. Os partidos seriam pouco coesos, indisciplinados e organizados fundamentalmente para atender interesses pessoais de alguns líderes (MAINWARING, 1991).

Um aspecto amplamente destacado na literatura que trata deste sistema refere-se às constantes trocas de legendas entre os parlamentares. O objetivo deste artigo é explorar a relação entre essas "migrações" e as regras estabelecidas pela legislação partidária no que diz respeito à fixação dos prazos de acolhimento de novas filiações e aos critérios a serem obedecidos para efeito da distribuição do tempo de propaganda gratuita no rádio e na televisão.

Lima Júnior (1993), analisando como se dá a composição partidária nas Casas Legislativas no Brasil pós-redemocratização, destaca que, no

\footnotetext{
1 Este artigo beneficiou-se de várias contribuições. O curso “Temas de análise do Brasil pós-1964”, ministrado pelo Professor Fernando Limongi, no Departamento de Ciência Política da Universidade de São Paulo, bem como seus comentários à primeira versão do trabalho foram de inestimável ajuda. Agradeço a leitura e os comentários dos membros do Grupo de Política do CEBRAP. Este artigo foi apresentado no Segundo Encontro da Associação Nacional de Ciência Política, realizado na PUC-SP, 20 a 24 de novembro de 2000 .
}

decorrer dos anos oitenta, outros fatores que não os resultados eleitorais modificaram profundamente o perfil partidário da Câmara (LIMA JÚNIOR, 1993, p. 80). Segundo o autor, os partidos que surgiram após o fim do regime militar são decorrentes de quatro processos:

1) transformação dos partidos anteriormente vigentes (o MDB transformou-se no PMDB e a ARENA no PDS);

2) confiança e credibilidade na mudança do regime (com o fim do bipartidarismo, surgiram PT, PDT, PTB e, posteriormente, o PSB, PCB, PC do B, PDC e PL);

3) cisões intrapartidárias - alguns parlamentares oriundos do PMDB uniram-se na formação do PP, que após um curto período reintegrou-se novamente ao PMDB; o PFL, que foi uma dissidência do PDS e o PSDB, dissidência do PMDB;

4) razões de oportunidade política individual: surgimento de pequenos partidos, especialmente na legislatura 1986-1990, que não disputaram sequer uma eleição legislativa federal (idem, p. 68).

A composição das Casas Legislativas seria decorrente da liberalização excessiva da legislação eleitoral e partidária, que não coíbe os excessos do comportamento individualista dos parlamentares, culminando com um sistema partidário que 
dificulta a evolução da vida partidária, porque os partidos adquirem um caráter de algo plenamente descartável. Nas casas legislativas vale o parlamentar individual, não os partidos. Assim, a representação de um número expressivo de partidos no Congresso tem consequiências políticas significativas:

a) "afastamento do sistema partidário parlamentar do sistema partidário eleitoral;

b) migração individual dos parlamentares entre os partidos;

c) enfraquecimento dos partidos, em virtude da introdução, ou do reforço, de uma perspectiva essencialmente individualista no processo político-parlamentar;

d) consequiências institucionais relacionadas com as dificuldades crescentes para a obtenção de consenso e, conseqüentemente, para a formação de maiorias minimamente estáveis, uma vez que enfraqueceram, dentro das instituições parlamentares, os partidos políticos e suas lideranças institucionais". Esse aspecto seria corroborado pelo fato de os grandes partidos - PSDB, PMDB e PFL - serem majoritários, mas controlarem, percentualmente, um número de cadeiras cada vez menor, dificultando a composição de maiorias de apoio ao presidente (idem, p. 80).

O resultado final é dos mais sombrios: a representatividade e a legitimidade do Congresso Nacional são postas em xeque; há "razoável divórcio entre a opinião pública, em sua expressão eleitoral, e a composição partidária da Câmara. É princípio essencial da democracia representativa liberal que à opinião pública expressa em votos corresponda uma distribuição de cadeiras por partidos que traduza, adequadamente, os resultados eleitorais. Este princípio assegura a representatividade do Legislativo" (ibidem).

A pergunta que daí decorre é: qual a importância em se assegurar uma melhor representatividade do Legislativo? Uma resposta simples seria que os eleitores delegam poderes a um representante, para que este defenda seus interesses. Defender interesses na arena legislativa implica conseguirse aprovar políticas, ou, no limite, impedir que políticas que não sejam do interesse do representado sejam aprovadas. Se essa premissa estiver correta, não deriva, como quer Lima Júnior, que a representatividade do Legislativo esteja abalada em razão do grande número de partidos, mas antes de o Legislativo não conseguir fazer com que os interesses que ele representa sejam atendidos. Cabe, portanto, investigar as razões que impedem ou dificultam a ação dos partidos em representar esses interesses. Em outras palavras, cabe indagar o que o distanciamento entre a vontade eleitoral e a composição partidária do Congresso acarreta na prática da vida parlamentar no Legislativo.

O processo decisório no legislativo federal brasileiro caracteriza-se por uma alta centralização dos trabalhos legislativos em torno da Mesa Diretora e do Colégio de Líderes (FIGUEIREDO \& LIMONGI, 1999). Embora formalmente as Comissões Permanentes sejam dotadas de poderes que teoricamente possibilitariam maior influência do parlamentar individual, a ação do Colégio de Líderes e da Mesa neutraliza este poder, seja através dos pedidos de urgência (retirando das comissões os projetos encaminhados à sua apreciação), seja através da participação nos trabalhos das comissões (encaminhando votação ou requerendo verificação de quorum) (artigo $9^{\circ}$, parágrafo $4^{\circ}$ do Regimento Interno da Câmara dos Deputados); ou pelo controle exercido pela Mesa, encarregada de definir os projetos que, aprovados nas comissões, entrarão ou não na Ordem do Dia.

Poder-se-ia contra-argumentar que o elevado número de partidos atrapalharia um possível consenso no Colégio de Líderes, questão de difícil comprovação empírica, pois as reuniões dos líderes são secretas. Seja como for, o que se sabe é que o partido com bancada inferior a um centésimo não tem direito a indicar um Líder (artigo $9^{\circ}$, parágrafo $4^{\circ}$ do Regimento Interno), o que formalmente impede que representantes dos pequenos partidos participem das reuniões de liderança.

O elevado número de partidos, além de não afetar o processo decisório, não altera significativamente a distribuição de postos institucionais no Legislativo, seja na composição da Mesa Diretora, seja na distribuição das Presidências das Comissões Permanentes. A composição dessas instâncias leva em conta critérios de proporcionalidade partidária. De 1989 a 2000, alternaramse na presidência da Mesa Diretora da Câmara somente dois partidos - PMDB (02.fev.1989 a 03.fev.1993 e posteriormente de 02.fev.1997 até os dias atuais ${ }^{2}$ ) e PFL (de 02.fev.1993 a 
02.fev.1997).

No caso das presidências das comissões permanentes, a distribuição desses postos dá-se entre as maiores bancadas partidárias. No período entre 1989 e 1998, em nenhum momento a Presidência de uma comissão permanente foi ocupada por um parlamentar cuja bancada fosse inferior a 15 deputados, o que reforça o argumento de que, do ponto de vista da dinâmica interna dos trabalhos legislativos, um número expressivo de partidos, especialmente de pequenos partidos, não acarreta alterações significativas, quer na ocupação de postos institucionais relevantes, quer na dinâmica do processo decisório.

Há ainda quem afirme que é intrínseco ao sistema presidencialista pluripartidário partidos pouco disciplinados, "pois [...] quanto mais coesos e disciplinados forem os partidos, menor a probabilidade de construção, pelo Presidente eleito, de uma base multipartidária ampla, necessária à sustentação governamental, e maior a probabilidade de contradições acumuladas e de impasse e imobilismo entre o presidente e o Congresso" (TAVARES, 1998, p. 291).

Alguns mitos do nosso sistema partidário vêm caindo por terra, na medida em que avançamos na conclusão de pesquisas empíricas. Dados de Figueiredo e Limongi (1999, p. 113) indicam que a disciplina partidária existente é suficiente para tornar o plenário previsível. O Congresso brasileiro, no período pós-88, não parece ser o reino do parlamentar individual. As indicações de votação das lideranças tendem a ser apoiadas pelas respectivas bancadas. Além do mais, o mapeamento das indicações dos votos das lideranças permitiu demonstrar que os partidos brasileiros distribuemse de maneira coerente num continuum ideológico. Podemos falar em partidos de direita, de centro e de esquerda, seja para as grandes bancadas partidárias, seja para os pequenos partidos (FIGUEIREDO \& LIMONGI, 1999, p. 75).

De acordo com Nicolau (1996, p. 98), a elevação das taxas de fragmentação no período 198094 foi motivada pela intensa troca de legendas entre os parlamentares. Mas se por um lado essa rotatividade é vista como sinal de pouca institucio-

2 Deve-se levar em conta que este artigo foi escrito em novembro de 2000, antes, portanto, da eleição de Aécio Neves (PSDB-MG) para a Presidência da Câmara dos Deputados (N. R.). nalização do sistema partidário, por outro ela foi funcional por facilitar o processo de ampliação e sustentação parlamentar do Executivo.

Em resumo, o fato de existir um número excessivo de partidos parece não alterar significativamente a dinâmica do processo decisório, a ocupação de postos institucionais, o grau de disciplina partidária ou ainda a composição dos ministérios. Falta-nos, no entanto, compreender por que surgem e desaparecem tantos partidos na arena parlamentar. Que razões têm parte dos parlamentares para trocarem freqüentemente de partido?

No Brasil, parte dos especialistas tende a explicar a migração partidária em razão da permissividade da legislação, e como um dos sintomas de nossa baixa institucionalização partidária (LAMOUNIER \& MENEGUELLO, 1986; MAINWARING, 1991; LIMA JÚNIOR, 1993). Para outros, algumas características do sistema partidário brasileiro podem ser resultantes da própria organização dos trabalhos legislativos (FIGUEIREDO \& LIMONGI, 1999; SCHMITT, 1999). Nesses termos, a migração partidária poderia ser vista como uma tentativa de o parlamentar maximizar suas chances na carreira política, uma vez que há poucas oportunidades para ele individualmente influenciar o processo de tomada de decisão, e assim adquirir dividendos que possam ajudá-lo na consolidação de sua carreira política.

Sob essa perspectiva alguns autores apresentaram explicações alternativas ao fenômeno das migrações partidárias. Para Araújo (2000, p. 59), "o sentido [das migrações] apenas parece seguir as tendências mais gerais da política nacional. A disputa pelo e o apoio ao Executivo parece explicar parte da flutuação das migrações partidárias". Melo (1999), por sua vez, chama a atenção para os arranjos institucionais que serão fundamentais para se entender a ação dos congressistas.

Além de demonstrar que não há uma razão única para as migrações, esses autores sugerem que alguns fatores podem vir a ser possíveis explicações para o fenômeno: 1) a expectativa de o parlamentar ter maiores chances de ser reeleito (MELO, 1999; SCHMITT, 1999); 2) rearranjos internos ao Legislativo logo após as eleições (entrada de suplentes e sua posterior realocação nos partidos que estão organizados no Legislativo), e 3) busca de posições institucionais no interior das Casas Legislativas. 
Nosso objetivo é explorar a relação entre migração partidária e as regras estabelecidas pela legislação partidária, como possível fator explicativo de parte das mudanças ocorridas a partir de 1989. Concordamos com os autores que defendem o argumento de que a não coibição às trocas não pode ser tomada como a causa das migrações, mas não podemos ignorar que além de "incentivos" (participação no fundo partidário e tempo de propaganda gratuita na TV e no rádio), a legislação por vezes exigiu uma representação mínima no Congresso ou na Câmara, seja para que os partidos pudessem apresentar candidatos, seja para ter acesso à propaganda gratuita. Portanto, não é ausência da coibição, mas o ganho a ser obtido com a mudança o fator que explicaria a troca de legenda.

O texto está organizado da seguinte forma: a primeira seção é uma revisão da literatura sobre migração partidária. A segunda apresenta informações empíricas sobre as migrações, de modo a descrever o fenômeno. A terceira e última seção explora a relação entre as migrações partidárias, $\mathrm{o}$ calendário eleitoral e as exigências da legislação para que os partidos pudessem ter acesso à propaganda gratuita e à apresentação de candidatos às eleições.

\section{REVISÃO DA BIBLIOGRAFIA}

O sistema partidário brasileiro é apontado por parte da literatura como um sistema frágil e não institucionalizado, principalmente em razão do surgimento e desaparecimento de alguns partidos. A organização partidária é fraca, o personalismo e o populismo prevalecem, as elites políticas manifestam pouca lealdade aos partidos, a volatilidade eleitoral é alta, o enraizamento dos partidos na sociedade é frágil e as personalidades individuais predominam sobre os partidos e as campanhas (MAINWARING, 1994) ${ }^{3}$.

Uma primeira geração de autores que enfocam a migração condena o número excessivo de partidos, muitos deles com assento na Legislativo sem que tenham passado pelo crivo eleitoral. As trocas constantes de legendas pelos parlamentares seriam

\footnotetext{
3 A institucionalização do sistema partidário, nos termos propostos por Mainwaring (1994, p. 44), implica: “estabilidade da competição entre os partidos, a existência de organizações fortemente enraizadas na sociedade, o reconhecimento dessas organizações partidárias e das eleições como instituições legítimas na escolha dos governantes e a vigência de partidos que comportam regras e estruturas estáveis”.
}

expressões da fragilidade institucional dos partidos (MAINWARING, 1991; MENEGUELLO \& LAMOUNIER, 1986; LIMA JÚNIOR, 1993) 4 .

Um dos fatores explicativos da intensa troca de legendas estaria na permissividade da legislação partidária: facilidade para formação de partidos dentro do Congresso, a inexistência de fidelidade partidária obrigatória, possibilidade de alianças e coligações eleitorais, inexistência de barreiras ao acesso à primeira cadeira em eleições proporcionais e a eleição proporcional de lista aberta.

Um aspecto das migrações partidárias é que nem todos os partidos apresentam os mesmos índices de troca de legendas. Para Lamounier e Meneguello (1986) a variação estaria ligada à estrutura socioeconômica, ao maior ou menor atraso dos estados.

Mais recentemente, as migrações partidárias passaram a ser vistas por alguns autores como uma estratégia a ser utilizada pelos parlamentares, para maximizarem seu espaço político (ARAÚJO, 2000; MELO, 1999; SCHMITT, 1999). Reconhecem que a adoção de uma legislação mais permissiva dá aos parlamentares a possibilidade da mudança de legendas sem maiores custos, mas a legislação não explica porque as migrações partidárias se mantiveram de maneira acentuada, a partir da reacomodação do sistema partidário durante a década de 80 .

Para Araújo (2000) e Melo (1999) não há uma explicação unívoca para as trocas de legendas. "Condições conjunturais, contextuais e instituições políticas compõem o cenário mais amplo da análi$\mathrm{se}$, [mas,] na cadeia causal, tais fatores relacionamse de modo distinto com a troca de legendas. Nenhum deles é capaz de explicar a sua ocorrência. Nenhum pode ser apontado como tendo sido capaz de determinar os cursos de ação que se seguiram ainda que, especialmente no caso do arranjo institucional, tenham traduzido estruturas de incentivo, constrangendo certos comportamentos e possibilitando outros" (MELO, 1999, p. 16).

Para Araújo (2000, p. 59), parte das migrações poderiam ser explicadas pela "disputa e [pelo] apoio ao Executivo"; parte "pede a consideração das histórias políticas dos diferentes estados e da forma como suas elites se re-acomodaram na passa-

\footnotetext{
4 Nicolau (1996) refere-se às trocas de legendas como um dos fatores a contribuir para o aumento da fragmentação na Câmara dos Deputados.
} 
gem do bi ao pluripartidarismo". Para ele, "as trocas de siglas, em última análise, são determinadas pela interação destas duas forças, a nacional e a estadual, no interior do processo de transição do sistema pluripartidário" (ARAÚJO, 2000, p. 73).

O trabalho de Melo (1999) tem um duplo objetivo: mostrar porque parcela considerável dos deputados brasileiros passou a considerar a migração partidária como uma alternativa viável para a continuidade de sua carreira política, e discutir as consequiências do fenômeno para o funcionamento dos sistemas eleitoral e partidários brasileiros. Para o autor há duas razões que podem explicar o comportamento dos deputados no que se refere às trocas de legenda: "a) o processo de desestabilização que atingiu o recente sistema partidário brasileiro logo na sua primeira década de existência, e b) a percepção, pelo deputado, de que a mudança de partido seria uma oportunidade de maximizar suas chances de sucesso na carreira" (MELO, 1999, p. 04). Este último aspecto seria a variável explicativa mais relevante para as migrações partidárias. "Uma vez aceito que o deputado, $1^{\circ}$ ) toma suas decisões de forma a levar em conta o imperativo da sobrevivência política; $2^{\circ}$ ) enfrenta um cenário de grande incerteza eleitoral; $3^{\circ}$ ) pode alterar sua trajetória partidária sem maiores custos; é razoável esperar que ele examine a possibilidade de uma mudança de partido durante o mandato tendo como base uma avaliação acerca do impacto de tal atitude sobre a continuidade de sua carreira política. Ou, como propõem Lima Júnior (1993), Nicolau (1996) e Mainwaring (1991), que o deputado veja na mudança de partido uma oportunidade de maximizar suas chances eleitorais" (MELO, 1999, p. 94). Assim, a troca de legendas seria uma das estratégias dos congressistas, tal qual a apresentação de proposições ou de emendas (idem, p. 96).

Dado que houve ampliação da competição política e que o processo decisório no legislativo brasileiro centra-se no Executivo e no Colégio de Líderes, é razoável supor que "este mesmo arranjo pode também estimular o parlamentar a buscar um melhor posicionamento junto ao núcleo decisório do sistema, mudando, sempre que necessário, de partido. Se votar com o líder faz parte de uma estratégia racional de sobrevivência política, buscar um partido melhor posicionado na estrutura de poder da Câmara também pode fazer" (idem, p. 40).

A validade desse argumento aplica-se apenas às migrações dos pequenos partidos para os grandes, pois, tendo em vista que a distribuição de postos institucionais (composição da Mesa Diretora e das Comissões Permanentes) no Congresso brasileiro é feita de acordo com critérios de proporcionalidade partidária, somente os grandes partidos conseguem ter acesso a esses postos. Sendo assim, essa estratégia não teria eficácia no caso de trocas entre os pequenos partidos. No entanto, a verificação sobre se quem mudou de partido obteve algum ganho, em termos de postos institucionais, ainda é uma questão que carece de pesquisas empíricas.

Outro aspecto explorado por Melo (1999) é a possibilidade das trocas de legendas serem motivadas pela intenção de se conquistar maior tempo de propaganda gratuita no rádio e na televisão. "A migração para um pequeno partido na Câmara - algo que já não acarretava custo eleitoral algum, dado os baixos níveis de identificação partidária e a possibilidade de se realizar coligações em todos os níveis - passou a ser uma potencial fonte de benefícios: aos deputados que eventualmente controlassem uma destas agremiações estaria garantido um precioso tempo na televisão, que tanto poderia ser utilizado para a projeção pessoal, como transformado em moeda de troca na negociação com os grandes partidos no processo de formação das coligações" (MELO, 1999, p. 37).

\section{RESULTADOS EMPÍRICOS}

Há dois momentos distintos desse processo de troca de legendas. Um refere-se ao processo de reacomodação partidária, fruto da legislação partidária do final da década de 70 e meados da década de 80: surgimento do PDT, PTB, PT, e posteriormente do PFL e do PSDB. Outro, que podemos chamar de trocas individuais, que se manifesta de modo mais acentuado nas legislaturas da década de $90^{5}$.

Nas três últimas legislaturas (1987-90, 199194 e 1995-98), a porcentagem de parlamentares que trocaram de partido manteve-se praticamente a mesma: cerca de $30 \%$ dos parlamentares que passaram pela Câmara Federal trocaram, pelo

\footnotetext{
5 Não considerei como trocas individuais os processos de reacomodação do sistema partidário: as cisões que deram origem ao PFL e ao PSDB, a trocada de nome do PCB para PPS, as fusões entre PDS e PDC que deram origem ao PPR, a do PST e PTR que originaram o PP, a do PPR com PP que resultou no PPB.
} 
menos, uma vez de partido (MELO, 1999, p. 175).

Há pequenas diferenças entre as bases de dados utilizadas por Araújo (2000) e Melo (1999), mas em linhas gerais as principais conclusões dessas pesquisas são:

1) quanto aos partidos e aos blocos ideológicos:

- os deputados de direita tendem a migrar de forma mais acentuada do que aqueles eleitos pela esquerda;

- os eleitos pela esquerda migraram com menor intensidade, mas mais de um terço dos que o fizeram foram para a direita do espectro. Por sua vez os deputados eleitos pela direita foram mais coerentes ao migrar permanecendo, mais de dois terços dos migrantes, dentro de seu campo ideológico (MELO, 1999, p. 179);

- a maior parte das migrações dá-se intrabloco ideológico, portanto o grau de liberdade para trocar de siglas não é absoluto; e "as fronteiras entre os blocos são mais nítidas do que aquelas entre os partidos" (idem, p. 152);

as migrações que ocorrem fora do mesmo bloco ideológico foram registradas no bloco da esquerda, e este comportamento anômalo pode ser explicado através do exame da bancada do PDT, que não só foi o partido de origem da maioria dos migrantes de esquerda como da quase totalidade dos que cruzaram o espectro (idem, p. 179; ARAÚJO, 2000);

2) relação entre migração partidária, ocupação de postos institucionais e tempo de mandato:

- deputados que não têm acesso aos postos institucionais da Câmara (membro da Mesa Diretora, presidente de Comissão Permanente, Líder Partidário com assento no Colégio de Líderes) migram mais do que os que têm acesso (MELO, 1999, p. 108);

• não há relação entre o número de mandatos do deputado e mudança partidária (idem, p. 101);

3) desempenho eleitoral:

- deputados que mudam de partido apresentam um desempenho eleitoral inferior aos demais (idem, p. 136). De acordo com Schmitt (1999, p. 185), "a chance de um deputado reeleger-se diminui se ele tiver se transferido para um outro partido";

- para Mello (1999, p. 144), "as mudanças de partido, vistas em seu conjunto, não melhoram as chances de sucesso do deputado. Tampouco tendem a piorá-las de forma significativa, a não ser quando se abandona um partido de esquerda ou um partido governista em direção à oposição";

. "a suposição de que nos estados de maior magnitude seria maior a migração não foi confirmada, verificando-se, pelo contrário, um percentual um pouco mais expressivo de migrantes nos estados de baixa magnitude - diferença, contudo, insuficiente para caracterizar a existência de alguma associação entre as variáveis" (idem, p. 181);

- a probabilidade de um parlamentar trocar de sigla é muito maior se ele tiver sido eleito por um pequeno partido (ARAÚJO, 2000, p. 46);

. "a probabilidade de um parlamentar disputar um novo mandato aumenta se ele tiver abandonado o partido pelo qual se elegeu, sobretudo se tiver efetuado mais de uma troca, independentemente da sua permanência no bloco ideológico a que pertence o seu partido de origem" (SCHMITT, 1999, p. 145);

4) regiões desenvolvidas versus não-desenvolvidas

- a hipótese de que os deputados das regiões menos desenvolvidas migrariam mais do que aqueles eleitos no Sul e Sudeste do país foi refutada para o período como um todo (1985-98), embora o mesmo não possa ser dito quando a análise recai sobre a primeira e última legislaturas examinadas (MELO, 1999, p. 180);

- estados com condições socioeconômicas semelhantes como Rondônia e Acre apresentam situações totalmente opostas. Os parlamentares do Acre migram menos que os de Rondônia; no Sul, o Paraná registra altos índices de migração partidária, enquanto Santa Catarina e Rio Grande do Sul têm taxas de troca de legendas bem menores.

III. AS MIGRAÇÕES PARTIDÁRIAS E O 


\section{CALENDÁRIOELEITORAL}

Desde a promulgação da Constituição de 1988 foram realizadas oito eleições: três eleições presidenciais, sendo duas casadas com eleições legislativas; uma eleição proporcional solteira e quatro municipais. Com exceção do pleito municipal de 2000, para cada uma delas houve uma lei específica, além de uma lei geral regulamentando a organização e o funcionamento dos partidos políticos.

Em 1997 foi promulgada a Lei 9 504, que passou a regulamentar tanto as eleições gerais (casadas) quanto as municipais. Até então os prazos para filiação dos futuros candidatos aos pleitos, e as datas para contagem da representação partidária no Legislativo, para efeito da distribuição do tempo de propaganda gratuita na TV e no rádio, eram objeto de intensa disputa política, como veremos adiante. Assim, toda a legislação que antecedeu a eleição de 1998 tinha um caráter provisório, estabelecia normas e prazos que normatizava pleitos específicos. A partir dessa lei, a expectativa era de que ela se tornasse uma norma permanente ${ }^{6}$.

Essa lei é mais exigente que as anteriores quanto à data limite para deferimento, pelos partidos, das novas filiações. Nas leis anteriores o prazo para filiação variou de seis a nove meses antes do pleito. Pela atual legislação exige-se que a filiação esteja deferida pelo menos um ano antes da eleição.

Outro aspecto importante introduzido por essa legislação diz respeito à data a ser considerada para a contagem da representação partidária, para efeito da distribuição do tempo de propaganda gratuita no rádio e na televisão. Passou-se a considerar o tamanho das bancadas partidárias no início da Legislatura que estiver em curso. Anteriormente, os prazos considerados ora eram a data de promulgação da lei, ora algum outro prazo préestabelecido pelos próprios parlamentares durante o processo de tramitação da lei. Em contrapartida à exigência de um prazo mais rígido (cerca de três anos antes do pleito), a representação partidária seria considerada somente na Câmara Federal. No entanto, o TSE, para a eleição de 1998, ignorou essa cláusula de barreira, permitindo que todos os partidos que apresentaram candidatos tivessem acesso à propaganda eleitoral gratuita. A legislação anterior ora exigiu representação no Congresso (Câmara e Senado), ora na Câmara e nas Assembléias Legislativas.

A propaganda eleitoral gratuita no rádio e na televisão foi regulamentada pela Lei 4115 de 22.ago.1962, mas a cada alteração na legislação eleitoral introduziram-se também novas modificações na distribuição do tempo de propaganda entre os partidos. Na eleição presidencial de 1989, todos os partidos que apresentaram candidatos, mas que não tinham representação no Congresso, tiveram acesso a trinta segundos de propaganda. O tempo restante foi dividido entre os partidos, com representação no Legislativo Federal, de acordo com critérios de proporcionalidade partidária.

Nas demais eleições, parte do tempo de propaganda foi distribuído eqüitativamente entre todos os partidos com representantes no legislativo e parte de acordo com a proporcionalidade partidária $^{7}$. O quadro abaixo resume as principais características dessas leis.

Quadro 1

\begin{tabular}{|c|c|c|c|c|c|c|c|c|}
\hline Pleito & Lei & $\begin{array}{l}\text { Data da } \\
\text { Eleição }\end{array}$ & $\begin{array}{c}\text { Exigência de } \\
\text { Representação } \\
\text { Legislativa para } \\
\text { Apresentação } \\
\text { de Candidatos }\end{array}$ & $\begin{array}{l}\text { Data para } \\
\text { registrar } \\
\text { candidato }\end{array}$ & $\begin{array}{c}\text { Prazo } \\
\text { para } \\
\text { Filiação }\end{array}$ & $\begin{array}{l}\text { Tempo de } \\
\text { propagan- } \\
\text { da gratuita }\end{array}$ & $\begin{array}{c}\text { Exigência de Repre- } \\
\text { sentação } \\
\text { para acesso } \\
\text { à propaganda }\end{array}$ & $\begin{array}{l}\text { Distribuição do Tempo de } \\
\text { Propaganda entre os partidos }\end{array}$ \\
\hline $\begin{array}{c}\text { Presi- } \\
\text { den- } \\
\text { cial }\end{array}$ & 7773 & $\begin{array}{c}15 . \\
\text { nov. } \\
1989\end{array}$ & Não & $\begin{array}{l}17 . \\
\text { ago. } \\
1989\end{array}$ & $\begin{array}{l}\text { Sem } \\
\text { infor- } \\
\text { mação }\end{array}$ & $\begin{array}{c}\text { 140' diários } \\
\text { (Res. TSE } \\
\text { 15580) }\end{array}$ & \begin{tabular}{|c} 
Representantes no \\
Congresso em \\
05.abr.1989, sendo que \\
seriam considerados as \\
adesões ou coligações \\
realizadas até \\
17.ago.1989
\end{tabular} & \begin{tabular}{|} 
Partidos sem representação no \\
Congresso: $30 "$ \\
20 congressistas: 5' $^{\prime}$ \\
De 21 a 60: 10' \\
De 61 a 120: 13' \\
De 121 a 200: 13' \\
Acima de 200: 22
\end{tabular} \\
\hline
\end{tabular}

6 Até este momento tem prevalecido essa expectativa, visto que para as eleições municipais de 2000 não foi promulgada nenhuma nova lei regulamentando o pleito. Resta saber se a Lei 9504 permanecerá para as próximas eleições.
7 De acordo com Schmitt, Carneiro e Kuschnir, (1999, p. 291), "Desde 1996 [...] as emissoras passaram a levar ao ar, durante o período de campanha, inserções comerciais curtas (de 15 ou 30 segundos), contendo mensagens ou propaganda dos partidos". 


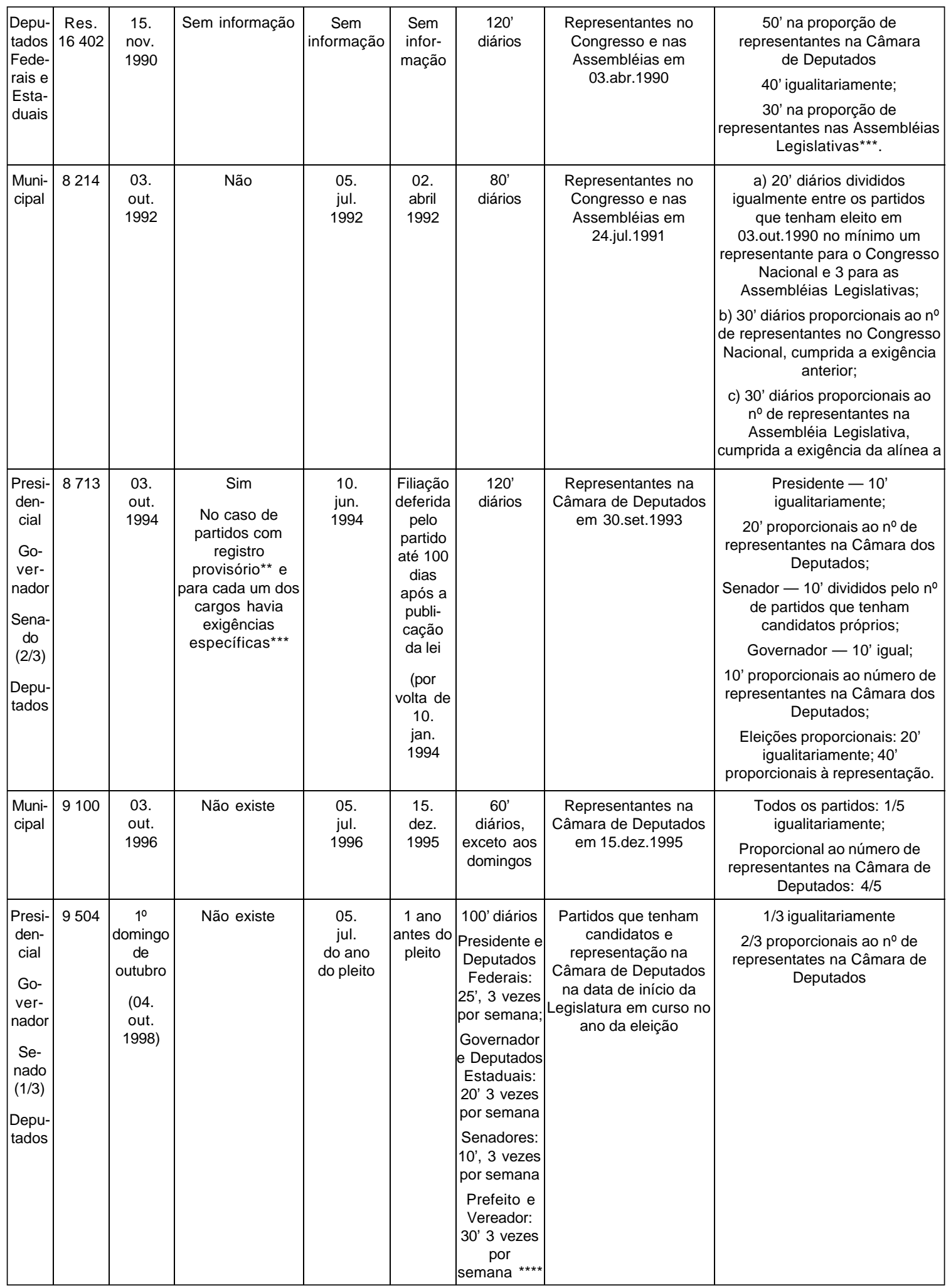

Fonte: Leis Eleitorais.

* Distribuição diferenciada para o Distrito Federal, Amapá e Roraima (artigo 27, inciso Il, da Resolução 16402 ).

** Partido com registro definitivo ou provisório (neste caso, desde tenha pelo menos 1 representante na Câmara dos Deputados em 30.set.1993).

*** Para o cargo de Presidente, o partido com pelo menos $5 \%$ dos voto apurados na eleição de 1990 para a Câmara dos Deputados, não computados os brancos e os nulos, distribuídos em pelo menos $1 / 3$ dos Estados; ou partido que contasse em 30 .set. 1993 com representantes titulares na Câmara dos Deputados em número equivalente a pelo menos $3 \%$ da composição da Casa. Para Governador: o partido que atendesse a uma das exigências para candidato a Presidente ou o partido que tivesse obtido em 1990 , nas eleições estaduais, $3 \%$ dos votos apurados excluídos os brancos e nulos.

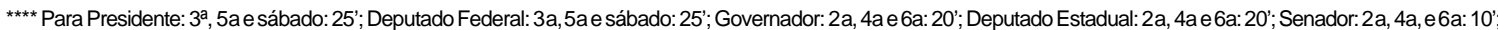
Prefeito: 2a, 4a, 6a:30'; Vereador: 3a, 5a e sábado: 30'. 
Como vimos anteriormente, parte da literatura que tratou do tema das migrações partidárias atribui à legislação partidária a causa de tais ocorrências. No nosso entender, a legislação não causa as trocas, mas cria determinados tipos de exigências ou gera incentivos que levam aqueles parlamentares interessados em maximizar suas chances de sucesso a trocarem de partido, sempre que avaliarem que a nova agremiação tem mais a lhes oferecer que a anterior.

$\mathrm{O}$ argumento a ser defendido neste trabalho é que essas exigências e os incentivos constantes na legislação eleitoral do período pós Constituição de 1988, podem ser tomados como fatores explicativos para parte das migrações partidárias. Adotamos como "exigência" o prazo préestabelecido para deferimento de filiação partidária, e como "incentivo" o tempo de propaganda gratuita no rádio e na televisão a que os partidos têm direito $^{8}$.

A julgar pelo fluxo de migração de legendas no decorrer dos meses, onde as maiores incidências de trocas coincidem com os prazos exigidos pela legislação, e pelos intensos debates travados, no que diz respeito ao estabelecimento desses prazos, acreditamos que há fortes indícios que parte dessas migrações podem ter sido motivadas por aquelas "exigências" e "incentivos".

A próxima seção apresenta dados sobre o fluxo das trocas de legendas, os períodos do ano de maior ocorrência, e parte dos debates parlamentares durante a tramitação das leis.

\section{AS MIGRAÇÕES PARTIDÁRIAS E OS PRAZOS ESTABELECIDOS NA LEGIS- LAÇÃO ELEITORAL}

A Lei 7773 de 08.jun.1989 regulamentou a eleição presidencial de 1989. Nessa eleição foram lançados 22 candidatos. Desses, oito não tinham representação no Congresso, mas mesmo assim tiveram acesso à propaganda gratuita. A eles foram concedidas inserções de trinta segundos, sendo que se facultava a soma desse tempo para utilização cumulativa até o limite de dois minutos, no caso de coligação.

\footnotetext{
8 Outro tipo de "incentivo" é a participação no Fundo Partidário introduzido pela Lei 9 504, que não será discutido aqui.
}

Esta lei estabeleceu como data limite para registro dos candidatos 17.ago.1989, e para efeito da distribuição do tempo de propaganda na televisão, 05.abr.1989, porém consideraria as adesões ou coligações realizadas até 17.ago.1989.

Não dispomos dos dados quanto às migrações partidárias no Senado, o que impede que façamos a reconstituição do tempo de propaganda, considerando o tamanho das bancadas existentes antes dos prazos limites estabelecidos pela legislação e as trocas de legendas. Há indicações de que o acesso à propaganda funcionou como um forte incentivo às migrações partidárias.

Tomando como exemplo o PRN (Partido da Reconstrução Nacional) do então candidato Fernando Collor, em 06.abr.1989, data inicial considerada para contagem das bancadas, esse partido não tinha nenhum representante na Câmara, o que lhe daria míseros 30 segundos de propaganda. No período de 06.abr.1989 a 17.abr.1989, somente na Câmara o PRN recebeu a adesão de 21 parlamentares. Com isto passou a ter direito a 10 minutos de propaganda gratuita. O PL (Partido Liberal), do então candidato Afif Domingues, parece também ter se beneficiado das trocas. Em 06.abr.1989 o partido contava com oito representantes na Câmara, o que lhe daria direito a cinco minutos de propaganda. Entre 06.abr.1989 e 17.ago.1989 o partido perdeu dois deputados e ganhou a adesão de outros quinze, passando a ter uma bancada de 21 deputados. Seu tempo de propaganda passou, portanto, de cinco para dez minutos.

O gráfico abaixo apresenta o fluxo das migrações partidárias no decorrer do ano de 1989 . O momento de maior intensidade das trocas ocorre entre os meses de julho e agosto de 1989, justamente na data limite para efeito das contagem da representação legislativa.

\section{Gráfico 1}

Migrações Partidárias em 1989

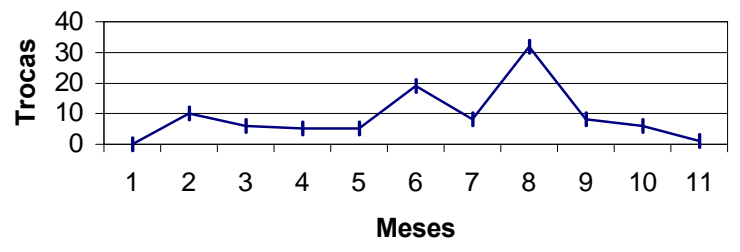

Fonte: Banco de Dados Legislativos - CEBRAP

A coincidência entre os momentos de maior intensidade das trocas de legendas e as datas-li- 
mite estabelecidas na legislação irá se repetir em todo o período posterior.

A eleição municipal de 03 de outubro 1992 foi normatizada pela Lei 8214 de 24.jul.1991 de autoria do Senador Mário Covas (PSDB-SP). A lei previa que 20 minutos do tempo de propaganda (do total de 80) fosse distribuído eqüitativamente entre todos os partidos, que tinham eleito em 03/10/90 no mínimo um representante para o Congresso e três para as Assembléias Legislativas.

Um dos temas polêmicos do projeto do Senado referia-se aos critérios a serem seguidos para efeito de registro dos candidatos. Em sua versão original o projeto previa que somente poderiam registrar candidatos ou participar de coligações, os partidos políticos com estatutos e diretório nacional registrados no Tribunal Superior Eleitoral (DIÁRIO DO CONGRESSO NACIONAL, 20.jun.1991, p. 10 208). Com isso, os partidos com registro provisório, como era o caso do Partido Verde, por exemplo, não poderiam apresentar candidatos.

O depoimento do relator na Câmara, Deputado Jurandyr Paixão, é claro quanto ao seu objetivo de coibir que partidos organizados provisoriamente tivessem acesso aos benefícios fornecidos pela legislação. "[...] Agasalhou-se ainda o escopo de se impedir, quando possível, a atuação, no pleito eleitoral vizinho, de legendas partidárias sem nenhuma expressão, carentes de representatividade e que, infelizmente, quando existiram, não passaram nunca das chamadas 'legendas de aluguel', meros balcões de agiotagem e estelionato político, que a experiência do passado comprovou, indesmentivelmente" (DIÁRIO DO CONGRESSO NACIONAL, 27.jun.1991, p. 11 659).

Quanto à distribuição do tempo de propaganda, o substitutivo do relator na Câmara exigia representação mínima no Congresso, nas Assembléias Legislativas e nas Câmaras Municipais (a versão do Senado não previa esta última instância). A contagem dos representantes tomaria como base os resultados das eleições de 03.out.1990 e de 15.nov.1988 (idem, p. 11 664). Pretendia-se com isso evitar as trocas de legendas.

É curioso notar como o debate em torno dessas questões permeia tanto os partidos de direita quanto os de esquerda. O Deputado Ricardo Izar (PL-SP) faz um clamoroso apelo ao presidente da Mesa, para que este prorrogasse o prazo de votação do projeto, pois, no seu entender, tais aspectos precisavam ser melhor discutidos. É este o seu depoimento: "Numa rápida leitura [...] verifiquei muitas irregularidades. Encontrei alguns artigos que irão prejudicar os pequenos e médios partidos. Por exemplo, com relação ao que trata do horário na televisão, o Senado esqueceu-se de incluir as Câmaras Municipais. O relator lembrou-se delas, mas deu-lhes apenas 10 minutos. O Senado está preocupado também em diminuir o horário político na televisão. Antes eram 120 minutos, agora o Senado os reduziu para 80 minutos. Quanto mais reduziu, pior para os pequenos e médios partidos, que ficarão sem o horário de televisão. Além disto existe outra falha no projeto quando estabelece um ano de domicílio eleitoral e um ano de inscrição partidária. Os pequenos partidos e os que estão em desenvolvimento não terão tempo para formar seus diretórios, e as novas lideranças que ingressarem nos partidos não terão tempo de fazê-lo" (DIÁRIO DO CONGRESSO NACIONAL, 28.jun.1991, p. 11 960).

O Deputado José Dirceu (PT-SP) e o Deputado Adylson Motta (PDS-RS) são dois dos defensores de um maior prazo de filiação. Aliás, o primeiro foi autor de uma emenda que excluía os partidos com registro provisório de apresentarem candidatos, sob protestos do Deputado Roberto Freire (PCB-PE). O argumento do Deputado José Dirceu é transcrito a seguir: a nova lei, "além de introduzir democraticamente, na divisão do tempo nas estações de rádio e nas emissoras de televisão, no uso de outdoors e na propaganda eleitoral em geral, critérios que permitirão a todos os candidatos e partidos ter acesso a esses meios de divulgação tivemos a preocupação de garantir que fossem cercadas as possibilidades de fraude nessa eleição, o que as experiências de 1989 e 1990 mostram ser moeda corrente em nosso país. Discute-se muito a questão da filiação e do domicílio eleitoral, principalmente a filiação um ano antes. Ora, o que vimos na eleição presidencial e na campanha de 1990 foram as legendas de aluguel, o uso e o abuso do prazo de filiação, para permear todo o processo eleitoral de pressões que não são democráticas. Agora, está havendo um verdadeiro corre-corre de legendas e candidatos, simplesmente para dividir, combater, comprar e chantagear outros partidos. Portanto, nada mais justo do que um ano de filiação partidária" (idem, p. 11 961).

Em sua versão final a lei manteve a exclusão dos partidos com registro provisório, o prazo limite 
para filiação foi de seis meses antes do pleito (abril de 1992) e a representação partidária considerada para efeito da distribuição do tempo de propaganda seria a de 24.jul.1991 (data de promulgação da lei).

O gráfico abaixo apresenta este fluxo. Por ele podemos ver que os maiores momentos de troca de legendas se dá no mês anterior ao prazo limite para filiação - março de 1992, assim como em abril, data máxima para a contagem da filiação.

\section{Gráfico 2}

\section{Migrações Partidárias em 1992}

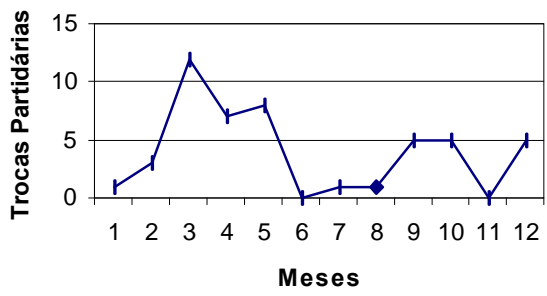

Fonte: Banco de Dados Legislativos - CEBRAP

Embora a taxa de migração comece a declinar após o estabelecimento do prazo de filiação, ela volta a apresentar patamares mais elevados entre os meses de agosto e outubro, período que coincide com o início do processo de impedimento do Presidente Collor.

A eleição de 1994 (para Presidente, Governador, Deputados e Senadores) foi regulamentada pela Lei 8713 de 30.set.1993. A única, dentre as aqui analisadas, que exigiu representação mínima na Câmara para que os partidos, com registro provisório, pudessem apresentar candidatos.

Esta lei é originária do PL 3 831/93, de autoria do Deputado José Dirceu (PT-SP). Sua primeira versão previa que somente poderiam apresentar candidato próprio às eleições para Presidente e vice-Presidente, os partidos que obtiveram, no mínimo, cinco por cento dos votos apurados na eleição de 1990 para a Câmara dos Deputados, não computados os votos em branco e os nulos, distribuídos em pelo menos um terço dos Estados, com um mínimo de dois por cento do total de cada um deles. Para concorrer ao cargo de Senador e Governador, os partidos que na eleição de 1990 para a respectiva Assembléia, tenham obtido três por cento dos votos apurados, excluídos os brancos e nulos (DIÁRIO DO CONGRESSO NACIONAL, 17.ago.1993, p. 16 410).
À versão original foi apresentado um substitutivo pelo relator, aprovado em votação simbólica, ressalvados os destaques e as emendas. Iniciado o processo de votação, seriam votados, por decisão da Mesa, preferencialmente três destaques: primeiro, o referente ao voto em branco; segundo, o incidente sobre o artigo que versava sobre a cédula eleitoral; e, terceiro, o relativo ao artigo que tratava de programas de TV (referente à proibição de utilização de montagens, truncagens e gravações externas), para posteriormente proceder-se à votação dos demais destaques.

Nesse momento o Deputado Luiz Salomão (Líder do PDT-RJ) pediu a palavra, anunciando que não foram apenas três os destaques fixados para serem votados nominalmente. Haveria um quarto destaque, com requerimento de preferência, referente à emenda que propunha uma nova redação, sugerindo que o número de representantes para a distribuição do tempo de propaganda, seria o correspondente ao resultado da eleição de 1990 para a Câmara dos Deputados.

O presidente da Mesa não confirmou esta informação e pediu que o Colégio de Líderes se pronuncie a respeito.

O Líder do PSDB, Deputado José Serra, informou que o acordo feito entre as lideranças dizia respeito apenas aos três destaques e que o que teria ficado acordado foi que a proporcionalidade obedeceria ao número atual de Deputados.

O Líder do PTB apoiou a proposta do Deputado Luiz Salomão, defendendo a posição que deveria ser mantida a distribuição do tempo na televisão e no rádio, nos moldes do que foi processado eleitoralmente no início da Legislatura, para que os deputados que mudaram de partido pudessem equilibrar seu desempenho partidário perante as eleições de 1994 (DIÁRIO DO CONGRESSO NACIONAL, 15.set.1993, p. 19 451). O argumento do Deputado Luiz Salomão foi o seguinte: a versão que prevaleceu no substitutivo "[...] contraria a intenção de fortalecimento dos partidos. Reforça, isto sim, o movimento dos trânsfugas, dos que leiloam seus passes, mudando de partido. Não me surpreende que o Líder do PP, Deputado Benedito Domingos, venha defender essa tese. Claro! Seu partido andou por aí arrebanhando deputados que estavam fugindo de suas agremiações. E mais: concordei com o Deputado Benedito Domingos em mudar a fórmula - originalmen- 
te prevaleceriam as eleições de 1990 - para as eleições atuais a fim de garantir ao PP a possibilidade de lançar um candidato à Presidência da República, bem como candidatos aos governos estaduais, pois seu partido ainda não é organizado. Mas de forma nenhuma posso concordar que esse princípio valha para a distribuição do tempo na televisão e para o fundo partidário" (idem, p. 19 452).

De acordo com depoimento dos demais Líderes, de fato a votação deste destaque não havia sido acordada no Colégio de Líderes. A questão passa a ser discutida entre os líderes que decidem votar o quarto destaque de autoria do deputado Luiz Salomão e do vice-Líder do PMDB Germano Rigotto. Eram favoráveis à representação de 1990 os líderes do PDT, PTB, PRN.

A versão final da lei exigiu uma representação mínima no Congresso para o caso dos partidos com registro provisório; para registro de candidato próprio à eleição para Presidente e vice, o partido que contasse, na data da publicação dessa Lei (30.set.1993), com pelo menos 5\% dos votos apurados na eleição de 1990 para a CD, não computados os brancos e os nulos, distribuídos em pelo menos um terço dos Estados; ou o partido que na data da publicação da lei contasse com representantes titulares na Câmara dos Deputados em número equivalente a, no mínimo, $3 \%$ da composição da Casa (15 deputados), desprezada a fração resultante desse percentual (inciso II, art. $5^{\circ}$, parágrafo $1^{\circ}$ da Lei 8713 ).

Nos casos de coligação pelo menos um partido tinha que atender a uma das condições, ou por partidos que somados atendessem as mesmas. Estas duas condições também eram exigidas para registro de candidatos a Senador, Governador e vice, para os casos em que o partido não tivesse obtido pelo menos $3 \%$ dos votos apurados nas eleições de 1990 para a respectiva Assembléia ou Câmara Legislativa.

O prazo limite considerado para filiação foi de 100 dias após a publicação da lei (por volta do dia 10.jan.1994) e a data-limite da contagem dos representantes na Câmara seria 30.set.1993 (data de promulgação da lei).
Os gráficos abaixo apresentam o fluxo migratório de legendas ao longo dos anos de 1993 e de 1994. O primeiro período de intensa troca de legendas refere-se a setembro de 1993, prazo de contagem de representantes na Câmara dos Deputados para efeito da distribuição do tempo de propaganda na TV; o segundo momento é janeiro de 1994, prazo limite para que os partidos aceitassem a filiação de novos membros.

\section{Gráfico 3}

Migrações Partidárias em 1993

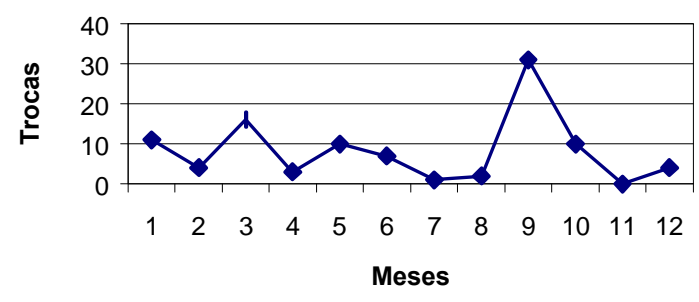

Gráfico 4

Migrações Partidárias em 1994

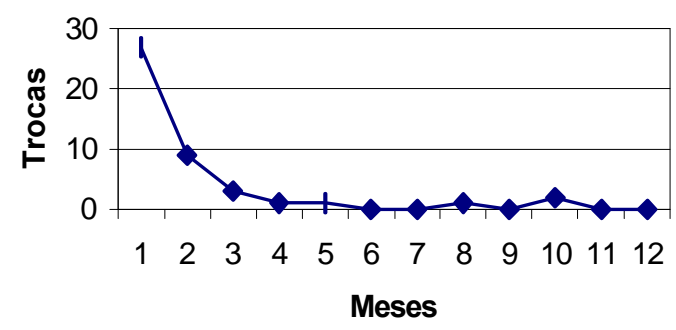

Fonte: Banco de Dados Legislativos - CEBRAP

$\mathrm{O}$ intenso debate que se seguiu quanto à definição da data a ser considerada para divisão do tempo de propaganda torna-se mais claro quando acompanhamos o seu efeito na distribuição do tempo entre os partidos. Os três principais defensores para que se adotasse a representação de 1990 tinham naquela época a seguinte representação: PDT, 46 deputados; PRN, 40 deputados, e PTB, 38 deputados. Em 15 maio de 1993, data em que esse debate deu-se, o PDT tinha 38 deputados, o PRN, 19 e PTB, 27, motivos de sobra para defenderem que prevalecesse a representação de 1990. A tabela abaixo apresenta a distribuição do tempo de propaganda gratuita entre os partidos, o tamanho das bancadas em 1990 e a representação considerada pelo TSE para cálculo do tempo de propaganda. 


\section{Quadro 2}

Candidatos presidenciais em 1994 e distribuição do tempo de propaganda na TV

\begin{tabular}{|c|c|c|c|}
\hline $\begin{array}{c}\text { Candidatos Presidenciais (c) } \\
\text { e nome da coligação }\end{array}$ & $\begin{array}{l}\text { Tamanho das bancadas } \\
\text { partidárias em } 1990\end{array}$ & $\begin{array}{l}\text { Tamanho da bancada } \\
\text { considerada pelo TSE }\end{array}$ & $\begin{array}{l}\text { Tempo na TV de acordo } \\
\text { com a resolução do TSE } \\
\text { (Res. } 14 \text { 499-A) }\end{array}$ \\
\hline $\begin{array}{l}\text { Luís Inácio Lula da Silva } \\
\text { FBPC - Frente Brasil Popular } \\
\text { pela Cidadania }\end{array}$ & $\begin{array}{c}\text { PT: } 35 \\
\text { PSTU: } 0 \\
\text { PPS: } 3 \\
\text { PSB: } 11 \\
\text { PV: } 0 \\
\text { PC do B: } 5 \\
\text { Total: } 54\end{array}$ & $\begin{array}{c}56 \text { representantes } \\
\text { na Câmara dos Deputados }\end{array}$ & $\begin{array}{c}\text { Divisão igualitária: 01:06:66 } \\
\text { Divisão proporcional: 02:25:73 } \\
\text { Tempo Total: 03:31 }\end{array}$ \\
\hline Leonel Brizola & PDT: 46 & $\begin{array}{c}34 \text { representantes } \\
\text { na Câmara dos Deputados }\end{array}$ & $\begin{array}{c}\text { Divisão igualitária: 01:06:66 } \\
\text { Divisão proporcional: 01:28:50 } \\
\text { Tempo Total: 02:34 }\end{array}$ \\
\hline Enéas Carneiro & PRONA: 0 & $\begin{array}{c}01 \text { representante } \\
\text { na Câmara dos Deputados }\end{array}$ & $\begin{array}{c}\text { Divisão igualitária: 01:06:66 } \\
\text { Divisão proporcional: 00:02:60 } \\
\text { Tempo Total: 01:08 }\end{array}$ \\
\hline Carlos Gomes & PRN: 40 & $\begin{array}{c}10 \text { representantes } \\
\text { na Câmara dos Deputados }\end{array}$ & $\begin{array}{c}\text { Divisão igualitária: 01:06:66 } \\
\text { Divisão proporcional: 00:26:03 } \\
\text { Tempo Total: 01:32 }\end{array}$ \\
\hline Hernani Fontoura & PSC: 6 & $\begin{array}{c}03 \text { representantes } \\
\text { na Câmara dos Deputados }\end{array}$ & $\begin{array}{c}\text { Divisão igualitária: 01:06:66 } \\
\text { Divisão proporcional: 00:07:80 } \\
\text { Tempo Total: 01:13 }\end{array}$ \\
\hline
\end{tabular}

Fonte: Nicolau (1998) e Resolução 14499 do TSE.

A eleição municipal de 1996 foi regulamentada pela Lei 9100 de 29.out.1995 e é originária do projeto de lei apresentado pelo Deputado Paulo Bernardo (PT). Em sua versão original o projeto previa como data limite para a escolha dos candidatos, pelos partidos, o período entre 02.abr.1996 e 30.maio.1996 (DIÁRIO DO CONGRESSO NACIONAL, 13.abr.1995, p. 6 346). As novas filiações partidárias deveriam ser deferidas pelos partidos até 30 dias após a publicação da lei, o prazo de domicílio eleitoral seria de um ano antes do pleito e, para efeito da contagem do tempo de propaganda, seria considerada a representação partidária com base no número de deputados eleitos em 03.out.1994.

Comparada à lei anterior, este projeto 1) aumentava de 10 para 15 minutos diários o tempo a que todos os partidos teriam direito de propaganda gratuita; 2) mais 15 minutos diários que seriam divididos igualitariamente entre os partidos que tinham elegido em 03.out.1994, no mínimo um representante para o Congresso e três para as Assembléias Legislativas; 3) 25 minutos diários na 
proporção do número de representantes no Congresso; 4) e mais 25 minutos diários na proporção do número de representantes nas Assembléias Legislativas, cumprida a exigência " 2 ".

Foram apresentadas 175 emendas ao projeto e, como não poderia deixar de ser, boa parte delas e dos destaques para votação em separado recaíram sobre o artigo que estipulava a data da eleição de 1994 como critério para contagem da representação partidária. Uma das emendas apresentadas e posteriormente aprovada foi aquela que indicava a data de 31.dez.1995 para efeito da representação. $\mathrm{O}$ depoimento de alguns parlamentares reforça a idéia de que este prazo visava a favorecer alguns partidos. $\mathrm{O}$ artigo que estabelece este prazo "monta um casuísmo, faz com que a representação parlamentar, que deve ser dimensionada pelo voto dado no dia da eleição, seja determinada em função da data de 31.dez.1995. Isso é para proveito dos partidos que se beneficiaram de deputados que os abandonaram depois de eleitos" (Matheus Schmicht, apud DIÁRIO DO CONGRESSO NACIONAL, 14.set.1995, p. 22 055).

Mais uma vez parece haver fortes indícios de que parte das migrações partidárias é motivada pela legislação eleitoral. No decorrer do ano de 1995, até novembro, as migrações partidárias giraram em torno de dez trocas mensais, alguns meses mais, outros menos. Será, no entanto a partir de meados do mês de novembro e principalmente em dezembro que as migrações ultrapassam dez trocas mensais. O gráfico abaixo apresenta a distribuição das trocas de legendas em 1995.

\section{Gráfico 5}

Migrações Partidárias em 1995

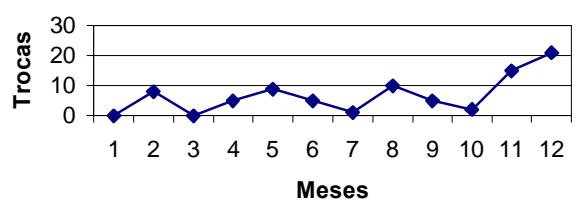

Fonte: Banco de Dados Legislativos - CEBRAP

As eleições de 1998 foram regulamentadas pela Lei 9504 de 30.set.1997. Os prazos a que já nos referimos anteriormente também ocuparam boa parte dos debates no decorrer da tramitação dessa lei. O projeto original é de autoria do Deputado Edinho Araújo (PMDB) e previa como datas-limite: a) para registro de candidatos, 15.jun.1998; b) para deferimento das filiações partidárias, 60 dias após a publicação da lei, e c) para efeito da distribuição do tempo de propaganda, a representação na Câmara de 15.dez.1997 (DIÁRIO DO CONGRESSO NACIONAL, 31.jan.1997, p. 3 296).

O tempo de propaganda gratuita seria assim distribuído:

Para Presidente:

- 10 minutos diários divididos igualmente entre os partidos e coligações;

- 20 minutos diários divididos proporcionalmente ao número de representantes de cada partido ou coligação na Câmara;

Para Senador:

- 10 minutos diários divididos igualmente entre os partidos e coligações que tenham candidato próprio;

Para Governador:

- 10 minutos diários divididos igualmente entre os partidos e coligações;

- 20 minutos diários divididos proporcionalmente ao número de representantes de cada partido ou coligação na Câmara;

Eleições proporcionais:

- 20 minutos diários divididos igualmente entre os partidos e coligações;

- 40 minutos diários divididos proporcionalmente ao número de representantes de cada partido ou coligação na Câmara.

A data limite para filiação e a da representação na Câmara para distribuição do tempo de propaganda geraram clamorosos depoimentos: o Deputado José Genoíno (PT-SP) assim se pronunciou: "É necessário ficarmos atentos ao critério para o cálculo do tempo na televisão. Todo o mundo fala da fidelidade partidária. Lei eleitoral não pode premiar a infidelidade. O critério para divisão do tempo na televisão tem de ser o do número de deputado no momento em que assumiram o mandato, porque corresponde ao número de votos que receberam na eleição de 1994. Usar como critério o número de deputados até o limite da lei eleitoral é premiar a infidelidade" (DIÁRIO DO CONGRESSO NACIONAL, 28.ago.1997, p. 25 348).

Quanto ao prazo de filiação, o Líder do PL 
propôs que se dilatasse o prazo para 60 dias após a promulgação da lei (a data do requerimento era de 28.ago.1997, levando-se em conta que o projeto deveria tramitar no Senado; se alterado, voltaria novamente à Câmara, provavelmente aquele prazo seria dezembro de 1997).

Esta dilatação de prazo contou com o apoio do deputado Sérgio Arouca do PPS-RJ, e com voto contrário, dentre outros, do PPB e do PT. O Deputado Gerson Peres (PPB-BA) assim se manifestou: "Não queremos estimular o troca-troca, não queremos incentivar o poder de aliciamento de parlamentares, pois o povo julga o troca-troca como se estivéssemos atrás de vantagens, por esta razão recomendava o voto 'não' ao destaque apresentado pelo Líder do PL” (idem, p. 25 433).

No mesmo sentido pronuncia-se o deputado João Paulo (PT-SP): "Precisamos colocar um paradeiro na troca de partidos, principalmente quando se aproxima o limite de filiação. O prazo de um ano já é bastante razoável. As pessoas já tiveram oportunidade. Já constituíram seus diretórios, já conviveram com a oposição, com a situação, com as organizações dos partidos na Casa. Para que dar mais dois meses, para que prolongar um mercado, como nós vimos em outras situações?" (DIÁRIO DO CONGRESSO NACIONAL, 28.jul.1997, p. 25 433).

Ao final prevaleceu que o prazo para filiação seria de um ano antes da data de realização do pleito, portanto 03/10/97, e a data a ser considerada para a contagem do tamanho das bancadas partidárias na Câmara, para a divisão do tempo de propaganda seria a do início da Legislatura. Para as eleições de 1998 seria 15/02/95.
As taxas de trocas de legendas no decorrer do ano de 1997 caíram acentuadamente em relação aos anos anteriores, mas, novamente em uma das datas-limite estipuladas pela legislação, encontramos altos índices de migração partidária, ou seja, exatamente no mês de outubro de 1997, data-limite para os partidos deferirem as novas filiações. O gráfico abaixo apresenta a distribuição das migrações ao longo do ano de 1997.

\section{Gráfico 6}

Migrações Partidárias em 1997

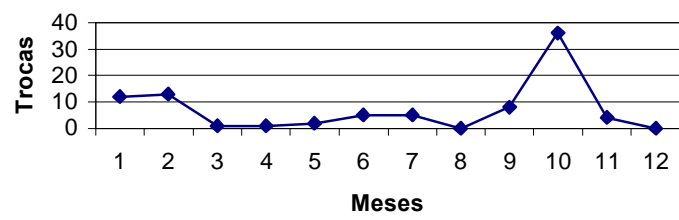

Fonte: Banco de Dados Legislativos - CEBRAP

Há fortes indícios de que parte das trocas de legendas foi motivada pelas normas estabelecidas na legislação, ao definirem os prazos limites para deferimento das novas filiações partidárias, e para a contagem da representação partidária para efeito da distribuição do tempo de propaganda gratuita na televisão e no rádio.

A tabela abaixo apresenta a quantidade de migrações partidárias ocorridas anualmente e a porcentagem de trocas que se deram retrocedendo a um mês das datas-limite. Com base nesses dados podemos afirmar que cerca de $30 \%$ das trocas de legendas ocorridas anualmente dão-se nesses prazos. A única exceção refere-se à data de 24.jul.1991, data para contagem da representação partidária na Câmara Federal, para distribuição do tempo de propaganda.

\section{Quadro 3}

Quantidade de trocas partidárias nos prazos estabelecidos pela legislação

\begin{tabular}{|c|c|c|c|}
\hline Eleições & Número de trocas anuais & $\begin{array}{l}\text { Quantidade de trocas } \\
\text { no prazo para contagem de } \\
\text { representação na } \\
\text { Câmara dos Deputados }\end{array}$ & $\begin{array}{c}\text { Quantidade de trocas no } \\
\text { prazo para filiação partidária }\end{array}$ \\
\hline Presidencial — 1989 & 104 & $\begin{array}{l}\text { 17.ago. } 1989 \\
\text { 30: } 28,8 \%\end{array}$ & $\begin{array}{c}\text { 17.ago. } 1989 \\
\text { 30: } 28,8 \%\end{array}$ \\
\hline $\begin{array}{l}\text { Deputados Federais, Estaduais } \\
\quad \text { e Governadores - } 1990\end{array}$ & 91 & $\begin{array}{l}\text { 03.abr. } 1990 \\
55: 60,4 \%\end{array}$ & Sem informação \\
\hline Eleição Municipal - 1992 & Trocas em 1991: 61 & $\begin{array}{l}\text { 24. jul. } 1991 \\
\text { 4: } 6,5 \%\end{array}$ & $\begin{array}{c}\text { Trocas em 1992: } 48 \\
\text { 02.abr.1992 } \\
\text { 17: } 35,4 \%\end{array}$ \\
\hline
\end{tabular}




\begin{tabular}{|c|c|c|c|}
\hline Eleição majoritária — 1994 & Trocas em 1993: 99 & $\begin{array}{c}30 . \text { set. } 1993 \\
31: 31,3 \%\end{array}$ & $\begin{array}{c}\text { Trocas em 1994: } 44 \\
\text { 10.jan.1994 } \\
\text { 11: } 25 \%\end{array}$ \\
\hline Eleição mmunicipal - 1996 & Trocas em 1995: 81 & $\begin{array}{c}\text { 15.dez.1995 } \\
\text { 22: } 27,1 \%\end{array}$ & $\begin{array}{c}\text { 15.dez.1995- } \\
\text { 22: } 27,1 \%\end{array}$ \\
\hline Eleição Municipal — 2000 & Trocas em 1999: 123 & $\begin{array}{c}\text { 15. fev. } 1999 \\
46: 37,3 \%\end{array}$ & $\begin{array}{c}\text { 03.out.1999 } \\
\text { 20: } 16,2 \%\end{array}$ \\
\hline
\end{tabular}

Fonte: Banco de Dados Legislativos do CEBRAP e Legislação Partidária

Se as suposições aqui feitas estiveram corretas, e permanecendo em vigência a Lei 9504 de 1997, um ano antes do pleito (prazo limite para deferimento das novas filiações) e a data de início da legislatura continuarão sendo períodos de intensa migração partidária.

\section{CONSIDERAÇÕES FINAIS}

Por que ocorre com tanta frequiência a troca de legendas na Câmara Federal Brasileira? Este artigo defendeu o argumento de que não é a ausência de coibição, aspecto já destacado por Araújo (2000), que motiva a "migração partidária", mas o ganho a ser obtido com a mudança o fator explicativo. A inferência é que o parlamentar que troca de legenda busca estar em um partido melhor posicionado para os futuros pleitos eleitorais, daí a correlação entre os principais momentos de troca de legendas e os prazos estabelecidos pela legislação para contagem do tamanho das bancadas partidárias com representação no Congresso, para definição do tempo de propaganda gratuita e para deferimento das candidaturas. Os partidos, nesse sentido, não são meras aglomerações políticas. Estar no partido $x$ ou $y$ em momentos-chave do processo eleitoral faz diferença.

Quais as conseqüências da intensa troca de legenda sobre o funcionamento do Legislativo? Uma delas seria de crise de governabilidade - situação em que o Executivo não conseguiria apoio para a aprovação de suas propostas. Não parece ser este o caso brasileiro, como têm demonstrado Figueiredo e Limongi (1999, p. 69): “o Presidente conta com inúmeras vantagens estratégicas que lhe permitem controlar a agenda decisória do processo legislativo".

Não há indicações empíricas, até este momento, de que o excessivo número de partidos ou de que as migrações partidárias tenham se constituído em obstáculo à ação do Executivo. Na verdade, podemos até mesmo suspeitar de que o Executivo tenha se beneficiado das trocas partidárias. Vale lembrar que, em fevereiro de 2000, o PSDB tornou-se a maior bancada parlamentar da Câmara, com 103 deputados, oito membros a mais que em 1999, além de ter constituído o maior Bloco Parlamentar, graças à união com o PTB (juntos contavam com 127 deputados), deixando para trás o PMDB e o PFL.

Naquele momento, início da segunda quinzena de fevereiro de 2000, estava em jogo a definição da composição das Comissões Permanentes da Câmara, que, como se sabe, adota o critério da proporcionalidade partidária para estabelecer a representação partidária, além de definir os cargos de Presidente e vice-Presidente, ou seja, os maiores partidos detêm o maior número de membros das Comissões, além de poderem escolher as Comissões que lhes interessa presidir.

Em suma, não são somente interesses estritamente individuais, e no mínimo discutíveis, o fato gerador de tantas trocas partidárias. Se queremos compreender melhor esse fenômeno, devemos nos deter mais atentamente ao que se ganha e ao que se perde no âmbito institucional.

Recebido para publicação em 27 de novembro de 2000.

Simone Diniz (dinizsimone@hotmail.com) é doutoranda no Departamento de Ciência Política da Universidade de São Paulo (USP) e bolsista da FAPESP. É também Assistente de Pesquisa (licenciada) do Centro Brasileiro de Análise e Planejamento (CEBRAP). 


\section{REFERÊNCIAS BIBLIOGRÁFICAS}

ARAÚJO, M. 2000. Mudanças partidárias. A evolução das migrações partidárias na Câmara dos Deputados - 1979/1999. São Paulo. Dissertação (Mestrado em Ciência Política). Universidade de São Paulo.

FIGUEIREDO A. C. \& LIMONGI, F. 1999. Executivo e Legislativo na nova ordem constitucional. Rio de Janeiro : Fundação Getúlio Vargas.

LAMOUNIER, B.\& MENEGUELLO, R. 1986. Partidos políticos e consolidação democrática : o caso brasileiro. São Paulo : Brasiliense.

LIMA JÚNIOR, O. B. 1993. A representação política e a composição partidária do Legislativo. In : - Democracia e instituições políticas no Brasil dos anos 80. São Paulo : Loyola.

MAINWARING, S. 1991. Políticos, partidos e sistemas eleitorais. Novos Estudos CEBRAP, São Paulo, n. 29, p. 34-58, mar.

MAINWARING, S. \& SCULLY, T. 1994. A institucionalização dos sistemas partidários na América Latina. Dados, Rio de Janeiro, v. 37, n. 1.

MELO, C. R. F. 1999. Retirando as cadeiras do lugar : migração partidária na Câmara dos Deputados (1985-1998). Belo Horizonte. Tese (Doutorado em Sociologia e Política). Universidade Federal de Minas Gerais.

MENEGUELLO, R. 1998. Partidos e governos no Brasil contemporâneo (1985-1997). São Paulo : Paz e Terra.

NICOLAU, J. 1996. Multipartidarismo e democracia : um estudo sobre o sistema partidário brasileiro (1985-1994). Rio de Janeiro : Fundação Getúlio Vargas.

. 1998. Dados eleitorais do Brasil (19821996). Rio de Janeiro : Revam.

SCHMITT, R. 1999. Migração partidária e reeleição na Câmara dos Deputados. Novos Estudos CEBRAP, São Paulo, n. 54, p. 127-146, jul.

SCHMITT, R., CARNEIRO, L. P. \& KUSCHMIR, K. 1999. Estratégias de campanha no horário gratuito de propaganda eleitoral em eleições proporcionais. Dados, Rio de Janeiro, v. 42, n. 2, p. 277-301.

TAVARES, J. A. G. 1998. O sistema político brasileiro. In : TAVARES, J. A. G. \& ROJO, R. E. (orgs.). Instituições políticas comparadas dos países do Mercosul. Rio de Janeiro : Fundação Getúlio Vargas.

\section{OUTRAS FONTES}

Diário do Congresso Nacional. Seção I, Câmara dos Deputados, Brasília, 20.jun.1991; 27.jun.1991; 28.jun.1991; 17.ago.1993; 15.set.1993; 13.abr.1995; 14.set.1995; 28.ago.1997. 